\title{
The Application of Micro-curriculum on College Education Teaching
}

\author{
Liyuan $\mathbf{L i}^{1}$ \\ ${ }^{1}$ Nanyang Institute of Technology, Nanyang, Henan, 473004
}

Keywords: micro-curriculum; college education teaching; application method

\begin{abstract}
With the continuous development of the Internet and multimedia, the teaching of micro-curriculum has been involved in the different disciplines of various colleges and universities, and has become the primary aid for education and teaching. The informatization of teaching has attracted people's attention. Micro-curriculum teaching has changed the traditional teaching model. In university curriculum, the form of the curriculum is mainly based on student practice. Combining the practical curriculum with the information concept of micro-curriculum is the main goal and direction of education and teaching reform.
\end{abstract}

\section{Introduction}

Education informatization is an important part of the national informatization strategy. The focus of school informatization construction is to enhance teachers' and students' informatization teaching ability and information technology application ability, and to strengthen the informatization level of professional and curriculum construction. Against such a backdrop, new teaching models such as flipping the classroom, admiring lessons, and micro lessons have emerged as the core of the Internet. Judging from the actual situation in China's education field, micro-curriculum is a relatively mature form of digital education resources. It has the characteristics of convenient communication, low development and production technology, low cost, and easy integration with other forms of educational resources. While it is easy to be directly accepted by teachers and students to improve the effectiveness of classroom teaching, it can also promote the rapid dissemination of quality education resources and promote the reform of education and learning methods [1].

Micro-class teaching model has many characteristics, then micro-class in the classroom teaching in the end how? This paper investigates and analyzes the use of micro lessons in classroom teaching in colleges and universities, the effects of classroom teaching, and the problems in the process of using the questionnaires. The aim is to improve the effects of classroom teaching by applying micro lessons in classroom teaching in colleges and universities. Make targeted policy recommendations.

Under the background of teaching information, teaching and research around micro-curriculum has become one of the focuses of college teaching. From a practical point of view, China has successively carried out two national college micro-curricular teaching competitions. Through the summary analysis of the competition, we can see that the teaching of micro-curriculum in China's universities is suitable for students in school, and micro lessons can improve teaching effectiveness. However, there are also problems such as the unscientific design of the teaching and the need for strong ability to develop micro-classes. From the perspective of theoretical research, domestic scholars' teaching research on micro lessons in college classrooms can be mainly attributed to the following aspects: First, combining micro-teaching with teaching reform, analyzing the relationship between micro-teaching and teaching reform; Second, analyzing the problems in the teaching of microteaching in colleges and universities, it is believed that the teaching of microteaching in China is still in the stage of exploration and development. There is an emphasis on the importance of externalities, the lack of student subjectivity, and the construction of micro-curriculums. Experience is not satisfactory and other issues should be mixed use of micro-teaching and classroom lectures, improve the teaching evaluation criteria of micro-classes; and so on. 


\section{The Related Research of Micro-curriculum}

Micro-course is a process of education and teaching based on the knowledge points in the classroom. It is a new type of teaching resource. The teaching objectives of the micro-curriculum are relatively clear. It integrates relevant knowledge materials, after-school exercises, feedback and commentary mechanisms, and includes teaching cases and courses and other resources. It shortens the time of course study and facilitates students' post-study activities in physical education courses. Practice, while the micro-teaching enhances the teacher's agility in thinking. While ensuring the focus and difficulty of classroom knowledge, it also stimulates students' interest in learning. The micro-teaching is different from the traditional teaching model. The traditional teaching model has a unitary nature. The micro-teaching focuses on the interaction between teachers and students. It can measure the student's learning situation in time and facilitate the development of the teacher's later courses. To a certain extent, it can enhance sports. Course quality [2].

Micro-curriculum refers to the entire course of teaching and learning activities carried out by teachers around a certain point of knowledge or teaching in the course of teaching in and out of the classroom according to the requirements of the new curriculum standards and teaching practice, with video as the main carrier. Micro-curriculum is a new type of teaching method that has emerged in recent years. It not only promotes the reform of the traditional teaching model, but also shows various advantages.

Compared with traditional teaching methods, micro-curriculum has the following characteristics: (1) Lively and lively in micro-teaching, teachers can produce images, and can also add voice-overs and related scene patterns according to the curriculum content, so that students can feel the lesson on the spot. "Duck-feeding" teaching methods are more vivid. (2) Concise Content Micro-curriculum Thanks to streaming media, the Internet can replace video and animation forms with cumbersome text narratives, highlighting knowledge points and skill points with the most concise content. (3) One-to-one teaching potential is available in the form of optional micro-teaching. Individual students can deepen and consolidate certain points of knowledge through video playback on their own basis. At the same time, they can selectively skip known content, save time and help improve learning efficiency. (4) Feedback function Micro-courses can be broadcasted on the Internet and other platforms. Students or teachers in the same school can be evaluated and adjusted according to feedback.

\section{The Advantages of Micro-curriculum in Higher Education}

Supported by multiple mobile devices. The characteristics of micro lessons are short, easy to store, easy to spread, etc. The video resources can be supported by a variety of mobile devices to facilitate students to download and learn. With short and accurate video content, students can easily capture the essence of knowledge and benefit student-specific learning. 2. Easy access to key and difficult knowledge. In the university curriculum, teaching objectives and content can be divided into blocks. Undergraduates can selectively focus on learning based on the video content of the operation of micro lessons, and to a certain extent can balance the gap between students and students. Teachers can sum up the key points in the course of video recording for college students to learn and download. 3. Get feedback in a timely manner. According to the characteristics of university classes, micro-curriculum can provide students with curriculum learning and evaluation of teachers. It is convenient for students to review the knowledge they have learned. Teachers can learn the students' knowledge and provide corresponding feedback information according to the students' feedback. 4. Can improve students' independent learning ability. With the development and popularization of the Internet, college students can download and learn resources according to their own curriculum needs. Micro lessons of mobility and freedom promote students' ability to develop self-improvement. 5. It can effectively promote the realization of flipping the classroom. College courses are mostly outdoor exercise training. The effective combination of micro lessons and flipping classrooms can promote the knowledge exploration between teachers and students within a 
limited class time. At the same time, it facilitates the collaboration between teams and teams after class. Classes are a teaching resource that is conducive to university teaching [3].

\section{The Application of Micro-curriculum in Higher Education}

Producing micro-classes for pre-class preparation, classroom learning and after-class review The teaching of university courses is a set of teaching processes consisting of pre-class preparation, classroom learning, and post-study review and development. The university course micro-lectures do not simply record, cut, and process small-video recordings of the original 45-minute course. Instead, they must carry out a brand-new instructional design based on the teaching objectives of the course and the design of students, and produce diverse and colorful teaching materials. Teachers should carefully analyze students' abilities and learning habits, sort out teaching difficulties, formulate teaching plans for micro lessons, and make good use of modern teaching equipment and resources such as computers, projectors, multimedia booths, slide projectors, online videos, and physical objects. It is difficult to understand, explain the profound things in a simple way, and abstract the specific teaching principles. It is used for the production of micro lessons and teaching applications to achieve the integration of subject expertise, teaching methods and technical means.

Highlight the fun, background and connection of pre-class preview micro-courses. Interest is the primary factor in ensuring the effectiveness of teaching in micro lessons and is the basis for inspiring students' follow-up learning activities. Therefore, we must intensify the interest in the micro-courses as a stepping-stone for preparatory activities and attract students to independently conduct micro-learning related learning. The background refers mainly to the use of micro lessons for the introduction of some abstract and rigorous concepts and theories to provide relevant background, theoretical history, and other background knowledge. Concerning refers to the fact that we must pay attention to the internal links between the knowledge points of the curriculum and different curriculum knowledge points in the production of micro-classes, and help students build the knowledge system of the curriculum and disciplines. For example, in the teaching of "spatial analytic geometry", we can use micro lessons to demonstrate the connection between related content and linear algebra knowledge to illustrate the geometric meaning of linear algebra knowledge.

To play a substitute and intensify the micro-courses in the classroom learning session. We can use micro lessons to explain some of the arduous abstract concepts and theories, replacing the tedious teaching of traditional teaching, so that more classroom time can be liberated to guide students in the learning activities of finding, analyzing, and solving mathematical problems. At the same time, we should carry out teaching design from the perspective of the overall curriculum, sort out the difficult points of curriculum teaching, and make use of the convenience and reproducibility of the micro-curriculum to reinforce the difficult and difficult aspects of teaching.

Guarantee the generality, practice, and expansion of the micro-courses after the class review. In each chapter of the course, we can sort the content of the chapters through micro lessons and help the students to further grasp the difficult and difficult points by means of example exercises. The problem-solving and problem-solving micro-classes are important forms for realizing the practice of the micro-courses in the review process. In addition, we should also pay attention to differences in student learning ability and level, and provide some extended content for students in need.

Micro-curriculum in the specific use of university physical education teaching, the implementation of the method should be combined with the use of principles, micro-courses need to combine classroom teaching methods, to a greater degree to meet the students' independent learning requirements, in order to improve students' ability to learn independently. Classroom teaching requires the use of school hardware, such as projectors, classrooms, and desks. Microteaching does not require these teaching hardware resources. Using online media can spread classroom teaching knowledge. Compared with classroom teaching, the teaching methods of micro lessons are more liberal. Students can study at different time and place, and their learning ability is very strong. Therefore, in the implementation of the method, micro-classes should combine classroom teaching methods, give play to their respective advantages, and improve the overall effect of physical 
education in universities [4].

\section{The Combination of Online Teaching Platform and WeChat Platform}

The essence of micro lessons is a kind of teaching experience made using online media technology. The nature of teaching in micro lessons is to use one or more platforms to spread teaching knowledge. This platform contains rich resources for micro lessons that students can use to move. The terminal equipment connects to the network, shares the micro-curriculum resources on the network platform, and independently learns the micro-teaching content. The choice of micro-course platform, based on the current existing network media technologies, mainly includes traditional network media platforms and novel WeChat public number platforms. The online teaching platform includes the entire teaching process resources such as instructional design, teaching content, teaching activities, and teaching evaluation. The online teaching platform is a relatively early teaching service. At present, online media has basically covered China's teaching. The traditional network teaching platform has its own advantages. It still occupies a mainstream position in China's university education. However, with the development of China's network information technology, it can be combined with the development of information technology to innovate on the basis of traditional network teaching. The public number platform is an innovation [5]. Wechat's current degree of use, almost everyone (except the majority of elderly people and children) will use WeChat social software, WeChat public platform can carry out interpersonal communication and communication, WeChat public subscription number allows people to understand and learn more The information includes educational institution information, cultural communication information, etc. The use of the WeChat public platform for micro-curriculum teaching in university physical education teaching enables students to more conveniently conduct learning and communication. Students can use their mobile WeChat platforms to learn the content of university micro-class teaching at any time. This is more convenient and faster. And a flexible modern learning and communication platform.

\section{Conclusion}

From the production to the application of micro-courses, it is necessary to consider the needs of the disciplines, the setting of courses, and the features and adaptability of the courseware itself. This will require teachers to invest a lot of time and energy. Therefore, colleges and universities should increase the special support for the use of micro-classes in the classroom teaching of teachers, for example, increase the proportion of class hours in classroom teaching of micro-classes, increase the rating of such courses, and even consider promotion of professional titles in micro-teaching. The proportion of information-based teaching and its proportions, etc., in order to reduce the pressure on college teachers teaching, research, while improving the level of information technology teaching in colleges and universities.

\section{References}

[1] Ma Shaofeng. Application of Micro-course in Physical Education[J]. Henan Agriculture, 2015(3):28-29.

[2] Han Xinying. Research on the Application of Micro Lessons in Physical Education [J]. Contemporary Sports Science and Technology, 2015(19): 114-115.

[3] Sun Qing. Application of Micro-curriculum in the Construction of Physical Education Curriculum [J]. Sports World (Academic Edition), 2014(09).

[4] Wei Xiaoyan, Du Rong. The status quo and countermeasures of college teachers' micro-curriculum construction in China[J]. China Distance Education, 2016(7):67-72.

[5] Xiao Juan, Wei Li. On Microteaching and Teaching Reform in Colleges and Universities [J]. Journal of High Education, 2015(18):127-128. 